\title{
The role of ischemic preconditioning in gene expression related to inflammation in a rat model of intestinal ischemia-reperfusion injury ${ }^{1}$
}

Celina Teresa Castelo Branco Couto de Miranda', Djalma José Fagundes", Edinaldo de Miranda"', Ricardo Santos Simõesiv ${ }^{\text {, Murched Omar Tahav }}$

'PhD, Assistant Professor, Medical School, Universidade Estadual do Piauí (UESPI), Teresina-PI, Brazil. Acquisition of data, manuscript preparation and writing.

"PhD, Full Professor, Division of Surgical Techniques and Experimental Surgery, Department of Surgery, Universidade Federal de São Paulo (UNIFESP), Brazil. Manuscript preparation and writing.

I'PhD, Assistant Professor, Medical School, UESPI, Teresina-PI, Brazil. Acquisition of data, manuscript preparation and writing.

IVPhD, Department of Morphology and Genetic, UNIFESP, Sao Paulo-SP, Brazil. Manuscript preparation and writing.

VPhD, Associated Professor, Surgical Technique and Experimental Surgery, UNIFESP, Sao Paulo-SP, Brazil. Manuscript preparation, final approval.

\begin{abstract}
Purpose: To investigate the gene expression related to inflammation on mice subjected to intestinal ischemia and reperfusion (I/R) and treated with ischemic preconditioning (IPC).

Methods: Thirty rats (EPM-Wistar), distributed in five groups of six animals each, were underwent anesthesia and laparotomy. The ischemia time was standardized in 60 minutes and the reperfusion time 120 minutes. IPC was standardized in 5 minutes of ischemia followed by 10 minutes of reperfusion accomplished before I/R. The control group was submitted only to anesthesia and laparotomy. The other groups were submitted to ischemia, I/R, ischemia + IPC and I/R + IPC. It was collected a small intestine sample to analyses by Quantitative Polymerase Chain Reaction in real Time (RT-qPCR) and histological analyses. It was studied 27 genes.

Results: The groups that received IPC presented downregulation of genes, observed in of genes in IPC+ischemia group and IPC+I/R group. Data analysis by clusters showed upregulation in I/R group, however in IPC groups occurred downregulation of genes related to inflammation. Conclusion: The ischemia/reperfusion promoted upregulation of genes related to inflammation, while ischemic preconditioning promoted downregulation of these genes.

Key words: Inflammation. Gene Expression. Ischemia. Reperfusion. Ischemic Preconditioning.
\end{abstract} Rats. 


\section{- Introduction}

During ischemia, there is loss of blood supply; target organs are deprived of oxygen and metabolic substrates, making it difficult to remove harmful substances from cells, such as reactive oxygen species (ROS) $)^{1,2}$. These substances play an important role in lipid peroxidation, compromising the structural and functional integrity of cell membrane and organelles, as mitochondria, with subsequent cellular damage. In the ischemic phase, hypoxic injury is the predominant process ${ }^{3-5}$.

Following the period of ischemia, the tissues adapt to the anaerobic metabolism. Restoration of the blood flow results in an excessive supply of oxygen, leading to the activation of macrophages in the vasculature and consequent generation of ROS. The key event of reperfusion injury is the activation of macrophages, the primary source of extracellular ROS. ROS are the main agents of reperfusion injury, causing endothelial damage and inflammatory cytokine release ${ }^{6,7}$.

The pathogenic process triggered by ischemia/reperfusion injury (I/R), like in dysfunction and a transplanted organ, myocardial infarction, or shock, and stimulates both immune and inflammatory pathways. The activation of inflammatory cells and cytotoxic cytokine expression are associated with I/R injury. The activation of these inflammatory mediators initiates several interconnected cascades, which are regulated by phosphorylation and dephosphorylation reactions. These phosphorylation-dependent signal transduction pathways initiate transcription of inflammatory and antiinflammatory genes to repair damaged cells ${ }^{8}$.

$I / R$ resulting from occlusion of the superior mesenteric artery may lead to damage to the intestinal mucosa and promotes release of inflammatory mediators, resulting in a systemic response. Intestinal lesions caused by I/R would mainly result from the following factors: loss of endothelial viability, adhesion of leukocytes and platelets to vessel walls, lesions on cell membranes and especially on organelles, as mitochondria. This process usually occurs in clinical situations, such as mesenteric ischemia, septic shock, extensive burns and intestinal transplantation. Thus, I/R plays an important role in the pathogenesis of systemic inflammatory response syndrome (SIRS) and Multiple Organ Dysfunction Syndrome (MODS), since it is associated with an increase in intestinal permeability, which is one of the causal factors of bacterial translocation that allows intestinal bacterium to burn to extra-intestinal sites ${ }^{9,10}$.

Several strategies have been studied with the aim of protecting organs from I/R injury. One of these is ischemic preconditioning (IPC). IPC is an adaptive response of tissue to brief periods of ischemia, which provides prior conditioning and serves to protect tissue from prolonged subsequent ischemic damage and reperfusion injury ${ }^{7,9}$. Ischemic tolerance is induced by the regulation of endothelial function, blood flow, reduced macrophage and neutrophil activity ${ }^{7,11}$. Adenosine, kinase C protein (KCP), cardiac shock proteins, antioxidant enzymes have been listed as mediators of IPC, however the precise role of each and the mechanisms are not fully elucidated ${ }^{12,13}$.

The clarification and understanding of the mechanisms used by several approaches to the protection conferred by IPC in different organs invariably requires knowledge of the changes in gene expression triggered during the process.

Some studies have proposed that the use of the quantitative real time polymerase chain reaction method (RT-qPCR) to evaluate specific gene expression during $I / R$ could be crucial to understanding the biochemical mechanism and the effects of protective 
treatments ${ }^{14-16}$.

By using Rat Endothelial Cell Biology PCR microarray, we investigate if intestinal I/R modifies gene expression encoding proinflammatory proteins in the rat enteric endothelial cells and if IPC treatment modifies this response.

\section{Methods}

The experimental protocol was submitted and approved by Universidade Federal de São Paulo (UNIFESP) Ethics Committee on Animal Research, protocol number 1815/08.

Adult, male Wistar rats $(n=30)$ weighing between 250 and $300 \mathrm{~g}$, from the Center For Experimental Models Development in Medicine and Biology-UNIFESP were used. The animals were kept under standard conditions of light, humidity, temperature and nutrition, and 6 hours before the experiment the supply of solid food was restricted. Intramuscular anesthesia was performed with a combination of xilazine $(10 \mathrm{mg} / \mathrm{kg})$ and ketamine $(60 \mathrm{mg} /$ $\mathrm{kg})$. Midline laparotomy was performed and exposure of the upper superior mesenteric vessels. Animals were randomly assigned to one of each five groups:

1 - Control group (CG, $n=6)$ : these animals were submitted to laparotomy without clamping of superior mesenteric artery;

2 - Ischemia group (IG, $n=6)$ : these animals were submitted to laparotomy and clamping of superior mesenteric artery for 60 minutes;

3 - Ischemia and reperfusion group (IRG, $n=6$ ): these animals were submitted to laparotomy and clamping of superior mesenteric artery for 60 minutes followed by 120 minutes of reperfusion;

4 - IPC followed by ischemia group $(I G+I P C, n=6)$ : the animals were subjected to one cycle of 5 minutes of ischemia and 10 minutes of reperfusion before the prolonged ischemia for 60 minutes by clamping the superior mesenteric artery;

5 - IPC followed by ischemia and reperfusion group (IRG+IPC, $n=6$ ): the animals were subjected to one cycle of 5 minutes of ischemia and 10 minutes of reperfusion before the prolonged ischemia for 60 minutes by clamping the superior mesenteric artery. This was followed by reperfusion for 120 minutes.

The ischemia was confirmed by observing the pale appearance of the clamped intestine and the lack of arterial beating. After ischemia, the clamp was removed, and the reperfusion was evaluated based on immediate color recovery and arterial beating. The surgical wound remained covered with wet gauze wrappings throughout the experiment to minimize evaporative loss. In all the groups, after the experiment, two intestinal segments of jejunum were removed, longitudinally opened, gently washed in saline solution $0.9 \%$, wrapped in aluminum foil, and immediately freezing in liquid nitrogen for storage in ultralow freezer. After this, the euthanasia of the animals was performed by anesthetic overdose.

\section{Real-time PCR}

Total RNA was extracted by using Trizol reagent. Then, $2 \mu \mathrm{g}$ of RNA was used for reverse transcription into CDNA. Real-time PCR was runner in the MX3000P thermal cycler (Applied Biosystems). PCR was performed according to the manufacture instructions in 96-well plates to detect the expression of 84 genes related to Endothelial Cell Biology (PARN015Z). The conditions for PCR were $95^{\circ} \mathrm{C}$ for $5 \mathrm{~min}, 40$ amplification cycles of $95^{\circ} \mathrm{C}$ for $30 \mathrm{~s}$, $58^{\circ} \mathrm{C}$ for $30 \mathrm{~s}$, and extension at $72^{\circ} \mathrm{C}$ for $45 \mathrm{~s}$. 8 -actin served as an internal reference and the expression of target genes was normalized to that of 6 -actin. Comparative $\mathrm{Ct}$ threshold method and the $\Delta \Delta C t$ was used for relative quantification $^{17,18}$. Expression gene data for each sample were evaluated in triplicate. The 
results of gene expression were presented like positive expression, an up-regulation (+), or negative expression, a down-regulation $(-)$. The software stablished the results three times above (hyper expression) or three times below (hypo expression) of limit allowed by the algorithm $\left[2^{\wedge}(-\Delta \Delta \mathrm{Ct})\right]$, like a biologically meaningful way.

\section{Statistical analysis}

The groups were compared using oneway analysis of variance (ANOVA) followed by Tukey's multiple comparison test to evaluate differences among groups.

\section{Results}

From a cluster of 27 genes related to the cascade of inflammation only eight showed down regulation (-) or up regulation (+). Data analysis by clusters showed upregulation in I/R group, however in IPC groups occurred down regulation of the genes related to inflammation. Such down regulation of the genes in groups that received IPC was observed in $100 \%$ of IG and IRG groups. The relative date of expression the eight genes related to inflammatory response in rat endothelial cell belonging to the IG, IG+IPC, IRG and IRG+IPC groups are listed in Table 1.

Table 1 - Expression of eight genes related to inflammatory response in the endothelial intestinal cell of rats of ischemic group (IG), ischemic and reperfusion group (IRG), preconditioning and ischemia group (IG+IPC) and preconditioning and ischemic and reperfusion group (IRG+IPC) compared to control group. Significant values of fold up $(+)$ or down $(-)$ regulation was marked in bold [2^(-Delta $\mathrm{Ct})]$.

\begin{tabular}{|c|c|c|c|c|c|c|}
\hline \multirow{2}{*}{\multicolumn{2}{|c|}{ Gene Symbol }} & \multirow[b]{2}{*}{ Gene description } & \multirow[b]{2}{*}{ IG } & \multicolumn{2}{|l|}{ GROUPS } & \multirow[b]{2}{*}{ IRG+IPC } \\
\hline & & & & IG +IPC & IRG & \\
\hline 1 & $\mathrm{Ccl} 2$ & Chemokine ( $\mathrm{C}-\mathrm{C}$ motif) ligand 2 & $-7.90 *$ & $-77.76^{*}$ & $-7.31 *$ & $-54.38 *$ \\
\hline 2 & Ccl5 & Chemokine ( $\mathrm{C}-\mathrm{C}$ motif) ligand 5 & +1.30 & $-5.44 *$ & -2.70 & $-4.51 *$ \\
\hline 3 & $\mathrm{Cx} 3 \mathrm{cl} 1$ & Chemokine ( $\mathrm{C}-\mathrm{X} 3-\mathrm{C}$ motif) ligand 1 & $-17.77 *$ & $-30.97^{*}$ & $-8.62 *$ & $-9.27^{*}$ \\
\hline 4 & $\mathrm{Cxcl} 2$ & Chemokine (C-X-C motif) ligand 2 & $-6.39 *$ & $-6.23 *$ & -3.76 & $-8.40^{*}$ \\
\hline 5 & Fn1 & Fibronectin 1 & $-20.98 *$ & $-17.14^{*}$ & $+24.57^{*}$ & $-9.74^{*}$ \\
\hline 6 & $\| 1 b$ & Interleukin 1 beta & -1.95 & $-16.03 *$ & +1.92 & $-8.59 *$ \\
\hline 7 & 116 & Interleukin 6 & $-8.09 *$ & $-20.08 *$ & +3.52 & $-14.74 *$ \\
\hline 8 & Sele & Selectin, endothelial cell & $-33.61 *$ & $-118.55^{*}$ & $+5.82 *$ & $-116.97 *$ \\
\hline
\end{tabular}

$*_{*}=p<0.05$ for the sample in triplicate values.

\section{- Discussion}

The complex mechanisms involving cellular death after the $\mathrm{I} / \mathrm{R}$ injury are not completely understood. Significant increases of content of ROS in tissues exposed to I/R have been observed, so that these tissues were showed increment of hydroxyl radicals, superoxide anions, and hydrogen peroxide, and associated with decreased antioxidant enzyme activities. ROS play a major role in the pathophysiology of the ischemic injury through oxidative damage to membrane lipids and proteins $^{19}$.

In vascular endothelial cells, thrombin induces increment of cytosolic $\mathrm{Ca} 2+$ levels and subsequent nitric oxide (NO) production. Because of the formation of cytotoxic products, 
such as free radicals and leukotrienes, excess intracellular $\mathrm{Ca} 2+$ triggers irreversible mitochondrial damage, inflammation and cell death and/or necrosis ${ }^{19}$.

Associated with a wide variety of pathologic conditions, $I / R$ injury of the gastrointestinal tract leads to a systemic inflammatory response due the bacterial translocation and endotoxin, responsible for the induction of cytokine cascades and proinflammatory mediators, which may cause dysfunction of multiple organs ${ }^{19}$.

Prolonged I/R rapidly causes substantial and irreversible intestinal tissue damage. Although restoration of blood flow to intestinal ischemic tissue is critical for tissue salvage, reperfusion also introduces inflammatory changes that exacerbates injury. IPC is a simple procedure that can promote cytoprotecting in critical organs and has clinical applications. Although intestinal IPC triggers powerful protective effects, mechanisms by which it alleviates intestinal injury remain to be elucidated ${ }^{20}$.

Several protocols of IPC have been established. The model with 5 minutes of ischemia and 10 minutes of reperfusion was chosen for this study because it has been demonstrated to protect organs against I/R injury, and also due to our aim to study precocious changes ${ }^{9}$. When the intestinal ischemia was fulfilled for 90 minutes, a lack of response occurred in the animal, which was unable to produce and release the inflammatory mediators; therefore, the animals that underwent IPC before 90 minutes of ischemia also had a theoretically greater capacity to provide a response to injury ${ }^{9}$. For this reason, we choose 60 minutes of ischemia, for allow to assess the tissue answer to IPC stimulus. Based on the studies that support that acute intestinal injuries are detectable at two hours after 45 minutes of intestinal ischemia, we choose two hours of reperfusion to evaluate the effect of IPC on the expression of inflammatory genes ${ }^{9}$.

Our results demonstrate a down regulation of genes related to inflammation at endothelial cell biology in the rats that underwent IPC (Table 1). The down regulation of these genes was observed in the IPC+IG and IPC+IRG groups, suggesting the hypothesis that IPC promotes the decreased expression genes that modulate the inflammatory damages produced by I/R. To realize our analysis, we sought to group genes according to the similarity of their previously characterized cellular activity. We focused in cluster proinflammation related gene that are relevant to intestinal I/R.

Thus, our results showed a marked inhibition in $\mathrm{Ccl} 2, \mathrm{Ccl} 5 \mathrm{Ccl} 5, \mathrm{Cx} 3 \mathrm{c} 1, \mathrm{Cxcl} 2$ , Fn1, II1b, $\| 6$ and Sele, genes encodes in both the IPC+IG and the IPC+IRG groups. The chemokines ( $\mathrm{Ccl} 2, \mathrm{Ccl} 5, \mathrm{Cx} 3 \mathrm{c} 1, \mathrm{Cxcl} 2)$ control the trafficking of innate immune cells between bone marrow, blood and peripheral tissues during inflammation. The significant hypo expression of $\mathrm{Ccl} 2$ in IPC characterizes mitigation of the chemotaxis to monocytes and basophils, like all of inflammation process ${ }^{21}$. The down regulation of Ccl5 in IPC groups suggests decreased release of inflammation mediators and consequent decreased inflammatory aggression in this group. The $\mathrm{Ccl} 5$ encodes proteins attractive to monocytes, promotes the monocytes histamine release, and attracts eosinophil ${ }^{22}$. $\mathrm{C} \times 3 \mathrm{cl} 1$ is a powerful attractive to $\mathrm{T}$ cells and monocytes and promote wrong adhesion of leukocytes to endothelial activated cells ${ }^{23,24}$. The down regulation of this genes in the groups with IPC was significant, below three times of the threshold, and also significant when compared to control group, which demonstrates the protection conferred by IPC. 
The Fn1 gene encodes a glycoprotein involved in migration and adhesiveness cell process. The up regulation of Fn1 was more accentuated in IRG group (+24.57), and the IPC was able to block significantly this increase (-9.74). $\mathrm{Cx} 3 \mathrm{cl} 1$ was also down regulated (-) in the IPC groups, more significantly in the IPC+IG group (-30.97).

The IL1 $\beta$ encodes a cytokine known like leukocytic pyrogen ${ }^{25}$. The significant down regulation of IL1 $\beta$ in IPC groups characterizes its protector effect against the inflammatory aggressions of I/R. Thus, Interleukin 6 (IL6) encodes a pro-inflammatory cytokine secreted by $\mathrm{T}$ cells and macrophages, and an antiinflammatory myosin, which effect is mediates through inhibitory effect on TNF $\alpha$ and IL1, besides of-activation of IL-1ra and IL10. Actually, there exist several data shown the implying of the IL6 as a mediator of several physiologic functions, like lymphocyte differentiation, cell proliferation and survival, beyond potentiate apoptotic signals ${ }^{26}$. The down regulation of IL6 in the IPC groups represented decreased of tissue inflammation.

The protein encoded by Sele gene in the endothelial cells is stimulated by cytokines as well as responsible for attract leukocytes to the inflammation sites, besides of mediating adhesion of cells to vascular wall. These proteins are part of selectins family ${ }^{27}$. In the groups that received IPC the down regulation expression of Sele was significant $($ IPC + IG = $-118,55$; IPC+IRG = -116,97), thus reducing of expressive form the inflammatory stimulus.

These results indicate that attenuation by IPC of intestinal I/R injury, previously demonstrated in rats, is related with ability of IPC in modulate expression of proteins involved in inflammatory responses, by up regulation $(+)$ of genes encoding inflammatory proteins and down regulation of genes encoding proinflammatory proteins.
The protective effect conferred by the PC procedure reduces the inflammatory damages caused by the I/R injury.

\section{Conclusion}

Ischemic preconditioning protect endothelial cell of rat intestine against ischemia/reperfusion injury by reducing inflammatory lesions.

\section{References}

1. Abu-Elmagd K, Bond G. Gut failure and abdominal visceral transplantation. Proc Nutr Soc. 2003;62:727-37. PMID: 14692608.

2. Komatsu H, Koo A, Ghadishah E, Zeng $\mathrm{H}$, Kuhlenkamp JF, Inoue $\mathrm{M}$, Guth $\mathrm{PH}$, Kaplowitc N. Neutrophil accumulation in ischemic reperfused rat liver: evidence for a role superoxide free radicals. Am J Physiol. 1992;262:G669-G76. PMID: 1373565.

3. Buja LM. Miocardial ischemia and reperfusion injury. Cardiovasc Pathol. 2005;12:170. PMID: 16009313.

4. Hossmann KA. Pathophysiology and therapy of experimental stroke. Cell Mol Neurobiol. 2006;26:1055. PMID: 16710759.

5. De Groot H, Rauen U. Ischemia-reperfusion injury: processes in pathogenetic networks: a review. Transplant Proc. 2007;39:481-4. doi: 10.1016/j.transproceed.2006.12.012.

6. Carden DL, Granger DN. Pathophysiology of ischaemia-reperfusion injury. J Pathol. 2000;190(3):255-66. PMID: 10685060.

7. Tapuria N, Kumar Y, Habib MM, Amara MA, Seifalian AM, Davidson BR. Remote ischemic preconditioning: a novel protective method from ischemia reperfusion injury - a review. J Surg Res. 2007;150(2):304-30. doi: 10.1016/j.jss.2007;12.747.

8. López-Neblina F, Toledo-Pereyra $H$. Phosphoregulation of signal transduction pathways in ischemia and reperfusion. J Surg Res. 2006;134:292-9. doi: 10.1016/j. jss.2006.01.007.

9. Pinheiro DNC, Fontes B, Shimazaki JK, Heimbecker AMC, Jacysyn JÁ, Rasslan $S$, Onteiro EFS, Utiyama EM. Ischemic 
precondiitioning modifies mortality and inflammatory response. Acta Cir Bras. 2016;31(1):1-7. doi: 10.1590/S0102865020160010000001.

10.Wang Z, Ji Y, Wang S, Wang R, Li Z, Kang $A$, Xu H, Shi M, Zhao MX. Protective effect of intestinal ischemic preconditioning on ischemia reperfusion-caused lung injury in rats. Inflammation. 2015;38(1):424-32. doi: 10.1007/s10753-014-0047-3.

11.Wang Shu-F, Li Guo-W. Early protective effect of ischemic preconditioning on small intestinal graft in rats. World J Gastroenterol. 2003;9(8):1866-70. doi: 10.3748/wjq. v9.i8.1866.

12.Um J W, Mathews JB, Song JC, Mun ED. Role of Protein kinase C I intestinal Ischemic preconditioning. J Surg Res. 2005;124:2890296. doi: 10.1016/j. jss.2004.10.001.

13.Tamion F, Richard V, Lacoume Y, Thuillez C. Intestinal preconditioning prevents systemic inflammatory response in hemorrhagic shock. Role of HO-1. Am J Physiol Gastrointest Liver Physiol. 2002;283:G40814. doi: 10.1152/aj.pgi.00348.2001.

14.Schoenberg $\mathrm{MH}$, Beger HG. Reperfusion injury after intestinal ischemia. Crit Care Med. 1993;21:1376-86. PMID: 8370303.

15.Bauer AJ. Transplantation- induced injuries of the intestinal muscularis and its innervations from preservation to chronic rejection. Transplant Proc. 1996;28:253941. PMID: 8907939.

16.Taha MO, Ferreira RM, Taha NSA, Monteiro $\mathrm{HP}$, Caricati-neto A, Oliveira-Júnior IS; Fagundes DJ. Ischemic preconditioning and the gene expression of enteric endotelial cell biology of rats submitted to intestinal ischemia and reperfusion. Acta Cir Bras. 2013;28(3):167-73. doi: 10.1590/S010286502013000300002.

17.Livak KJ, Schmittgen TD. Analysis of relative gene expression data using real-time quantitative PCR and the 2(-Delta Delta C(T)) Method. Methods. 2001;25(4):402-8. doi: 10.1006/meth.2001.1262.

18.Calió ML, Marinho DS, Ko GM, Ribeiro RR, Carbonel AF, Oyama LM, Ormanji M, Guirao TP, Calió PL, Reis LA, Simões Mde J, Lisbôa-Nascimento T, Ferreira AT, Bertoncini CR. Transplantation of bone marrow mesenchymal stem cells decreases oxidative stress, apoptosis, and hippocampal damage in brain of a spontaneous stroke model. Free Radic Biol Med. 2014;70:141-54. doi: 10.1016/j.freeradbiomed.

19.Bonservizi WGS, Koike MK, Saurim R, Felix GAA, Silva SM, Montero EFS. Ischemic preconditioning and atenolol on lung injury after intestinal ischemia and reperfusion in rats. Transplant Proc. 2014;46:1862-6. doi: 10.1016/j.transproceed2014.05.054.

20.Ji YY, Wang Shu-Feng, Wang Bao-Tai, Yang Zheng-Na, Zhou Xiao-Rong, Lei Ni-Na, Yue Wei-Na. Ischemic preconditioning ameliorates intestinal unjury induced by ischemia-reperfusion in rats. Worl J Gastroenterol. 2015;21(26):8081-8. doi: 10.3748/wjg.v21.i26.8081.

21.Zlotnik A, Yoshie O. Chemokines: a new classification system and their role in immunity. Immunity 2000;12:121-7. PMID: 10714678.

22.Donlon TA, Krensky AM, Wallace MR, Collins FS, Lovett $M$, Clayberger C. Localization of a human T-cell-specific gene, RANTES (D17S136E), to chromosome 17q11.2-q12. Genomics. 1990;6(3):548-53. PMID: 1691736.

23. Muro A, Chauhan AK, Gajovic S, Baralle FE. Regulated splicing of the fibronectin EDA exon is essencial for proper skin wound healing and normal lifespan. J Cell Biol. 2003;162(1):149-60. PMID: 169.1736.

24.Imai T, Hieshima K, Haskell C, Baba M, Nagira $M$, Nishimura $M$, Kakizaki $M$, Takagi S, Nomiyama H, Schall TJ, Yoshie O. Identification and molecular characterization of fractalkine receptor CX3CR1, which mediates both leukocyte migration and adhesion. Cell. 1997;91(4):521-30. PMID: 9390561.

25.Auron PE, Webb AC, Rosenwasser LJ, Mucci SF, Rich A, Wolff SM, Dinarello CA. Nucleotide sequence of human monocyte interleukin 1 precursor cDNA. Proc Natl. Acad Sci USA.1984;81(24):7907-11. PMID: 6083565.

26. Kamimura D, Ishihara K, Hirano T. IL-6 signal transduction and its physiological roles: the signal orchestration model. Rev Physiol Biochem Pharmacol. 2003;149:1-38. PMID: 12687404. 
27.Watson $\mathrm{ML}$, Kingsmore SF, Johnston $\mathrm{GI}$, Siegelman $\mathrm{MH}$, Le Beau MM, Lemons RS, Bora NS, Howard TA, Weissman IL, McEver RP, Seldin MF. Genomic organization of the selectin family of leukocyte adhesion molecules on human and mouse chromosome 1. J Exp Med. 1990;172:26372. doi: 10.1084/jem.172.1.263.

\section{Correspondence:}

Celina Teresa Castelo Branco Couto de Miranda

Rua Jaime da Botica, 3442

64.050-040 Teresina-PI Brasil

Tel.: (55 86)-99425-7001

celinatcbcm@ig.com.br

Received: Aug 09, 2018

Review: Oct 05, 2018

Accepted: Nov 08, 2018
Conflict of interest: none

Financial source: none

${ }^{1}$ Research performed at Division of Surgical Techniques and Experimental Surgery, Department of Surgery, Universidade Federal de São Paulo (UNIFESP), Brazil. 